\title{
Turbulent and Transitional Modeling of Drag on Oceanographic Measurement Devices
}

\author{
J. P. Abraham, ${ }^{1}$ J. M. Gorman, ${ }^{1}$ F. Reseghetti, ${ }^{2}$ E. M. Sparrow, ${ }^{3}$ and W. J. Minkowycz ${ }^{4}$ \\ ${ }^{1}$ School of Engineering, University of St. Thomas, 2115 Summit Aveune, St. Paul, MN 55105-1079, USA \\ ${ }^{2}$ ENEA, UTMAR-OSS, Forte S. Teresa, 19032 Pozzuolo di Lerici, Italy \\ ${ }^{3}$ Department of Mechanical Engineering, University of Minnesota, 111 Church Street SE, Minneapolis, MN 55455-0111, USA \\ ${ }^{4}$ Department of Mechanical and Industrial Engineering, University of Illinois at Chicago, Chicago, IL 60607, USA
}

Correspondence should be addressed to J. P. Abraham,jpabraham@stthomas.edu

Received 3 October 2011; Accepted 11 January 2012

Academic Editor: Guan Heng Yeoh

Copyright (๑) 2012 J. P. Abraham et al. This is an open access article distributed under the Creative Commons Attribution License, which permits unrestricted use, distribution, and reproduction in any medium, provided the original work is properly cited.

Computational fluid dynamic techniques have been applied to the determination of drag on oceanographic devices (expendable bathythermographs). Such devices, which are used to monitor changes in ocean heat content, provide information that is dependent on their drag coefficient. Inaccuracies in drag calculations can impact the estimation of ocean heating associated with global warming. Traditionally, ocean-heating information was based on experimental correlations which related the depth of the device to the fall time. The relation of time-depth is provided by a fall-rate equation (FRE). It is known that FRE depths are reasonably accurate for ocean environments that match the experiments from which the correlations were developed. For other situations, use of the FRE may lead to depth errors that preclude XBTs as accurate oceanographic devices. Here, a CFD approach has been taken which provides drag coefficients that are used to predict depths independent of an FRE.

\section{Introduction}

Oceanography requires data samples of ocean information such as temperature and salinity at a sufficiently large number of locations and times to ensure proper characterization of ocean properties. The creation of such data sets is constrained by the number of measurements made around the globe. It is also constrained by the duration of measurement activities. For climate monitoring for instance, continuous measurements on the order of decades is required to extract a signal-to-noise ratio sufficient to make judgments about global warming [1].

One of the most commonly used devices for taking ocean temperature measurements is the expendable bathythermograph (XBT). Approximately six million XBT devices have been launched over the past few decades. XBT devices contain a temperature-sensing element housed within a streamlined object which is launched into the ocean. The XBT falls through the water at approximately $7 \mathrm{~m} / \mathrm{s}$. During its descent, a copper wire is unspooled maintaining an electrical connection with a data processing station onboard a ship. Temperature information is transmitted through the wire and is stored for processing.

There are multiple varieties of XBT devices, each with a unique label. They are broadly separated into two classes (T4/T6/T7/T10/DB which are most common, then the FD, $\mathrm{T} 11$, and the T5 class). The major difference between the two classes is the size of the XBT body. Additionally, there are two main XBT manufacturers (LM-Sippican and TSK). Slight differences in the manufacturing processes between these two suppliers and variations in the processes since the 1960s have introduced some variation in the fall rates of the respective devices [2-6].

Biases in XBT measurements have been known for approximately 40 years. These include biases in the estimated depth as well as biases in temperature. The biases have led to errors in ocean-heat estimations reported in [2, 7-9]. Numerous efforts have been completed to reduce these biases and thereby increase the accuracy of oceanographic measurements made by XBT devices. These efforts have typically focused on improving the depth-time correlation of the FRE [10-13]. 
Very rarely have researchers focused on developing a dynamic model of the XBT during its descent with an analysis of buoyant, drag, and weight forces. Perhaps the most significant effort in this regard was by Green [14] who developed a model utilizing approximate drag forces which were taken from literature corresponding to streamlined bodies.

Here, a new approach is adopted. A dynamic model is developed and drag-coefficient information is taken from a computational fluid dynamic study. To the best knowledge of the authors, the computational approach is the first of its kind for XBT devices. The authors will investigate the impact of laminar-to-turbulent transition in the boundary layer of the XBT. Specifically, a comparison of drag coefficients for fully turbulent and transitional models will be performed. The resulting drag information will be used to predict depths on recent XBT experiments. The predicted depths will be compared with both the industry-standard FRE and with collocated and contemporaneous experiments using CTD devices which are considered the gold standard in oceanography.

\section{Fluid Dynamic Model}

Two approaches are taken in handling the simulations of fluid flow in the vicinity of the probe. The first method is based on the popular Shear Stress Transport (SST) model developed by Menter [15]. This model combines the seminal $\kappa-\varepsilon$ model of Launder and Spalding [16] in regions removed from the probe-water interface with the $\kappa$ - $\omega$ model in the boundary layer [17, 18]. The SST smoothly transitions between the two models to take advantage of their respective strengths. The $\kappa-\varepsilon$ typically provides more accurate results in the free stream and is less sensitive to the upstream flow conditions whereas the $\kappa-\omega$ method is more capable of handling the low-Re flow within the boundary layer.

The second method is a transitional model which was first exhibited by Menter et al. [19] and Menter et al. [20]. It was later developed by the present authors in a series of studies which extended its use to internal flows, flows with adverse pressure gradients in diffusers, and pulsating flows [21-30]. Both the SST method and the newly developed transitional method rely upon a control-volume solution method wherein conservation equations are developed at a multitude of elements which constitute the solution domain. Among the relevant equations are conservation of mass and momentum, which are expressed in tensor form as:

$$
\begin{gathered}
\frac{\partial u_{i}}{\partial x_{i}}=0 \\
\rho\left(u_{i} \frac{\partial u_{j}}{\partial x_{i}}\right)=-\frac{\partial p}{\partial x_{j}}+\frac{\partial}{\partial x_{i}}\left(\left(\mu+\mu_{\text {turb }}\right) \frac{\partial u_{j}}{\partial x_{i}}\right), \quad j=1,2,3 .
\end{gathered}
$$

Here, the term $u$ is the local velocity, $\rho$ is the fluid density, $p$ is the pressure and $\mu$ represents the molecular viscosity. In (2), turbulent motion has been accounted for by the introduction of the eddy viscosity. It is the definition of the eddy viscosity which characterizes the turbulence model. When the SST approach is taken, the eddy viscosity is found from:

$$
\mu_{\text {turb }}=\frac{a \rho \kappa}{\max \left(a \omega, S F_{2}\right)},
$$

where the terms $\kappa$ and $\omega$ are found from two new transport equations for turbulent kinetic energy and the specific rate of turbulence dissipation:

$$
\begin{aligned}
\frac{\partial\left(\rho u_{i} \kappa\right)}{\partial x_{i}}= & P_{\kappa}-\beta_{1} \rho \kappa \omega+\frac{\partial}{\partial x_{i}}\left[\left(\mu+\frac{\mu_{\text {turb }}}{\sigma_{\kappa}}\right) \frac{\partial \kappa}{\partial x_{i}}\right], \\
\frac{\partial\left(\rho u_{i} \omega\right)}{\partial x_{i}}= & A \rho S^{2}-\beta_{2} \rho \omega^{2}+\frac{\partial}{\partial x_{i}}\left[\left(\mu+\frac{\mu_{\text {turb }}}{\sigma_{\omega}}\right) \frac{\partial \omega}{\partial x_{i}}\right] \\
& +2\left(1-F_{1}\right) \rho \frac{1}{\sigma_{\omega^{2}} \omega} \frac{\partial \kappa}{\partial x_{i}} \frac{\partial \omega}{\partial x_{i}} .
\end{aligned}
$$

The term $P_{\kappa}$ represents the rate of production for the turbulent kinetic energy, $\kappa$. All of the $\sigma$ terms are Prandtl-like numbers for the respective transported variables, indicated by a subscript. The $F$ terms represent blending functions whose purpose is to allow the transition from the $\kappa-\varepsilon$ model away from the wall to the $\kappa-\omega$ model near the wall. The $S$ term refers to the magnitude of the shear strain rate. Taken together, (1)-(5) define the SST approach. This approach accounts for flow that is fully turbulent as it approaches the oceanographic probe.

The transitional model includes a slight variation to the SST method. The variation begins with a modified form of (4) which becomes

$$
\frac{\partial\left(\rho u_{i} \kappa\right)}{\partial x_{i}}=\gamma \cdot P_{\kappa}-\beta_{1} \rho \kappa \omega+\frac{\partial}{\partial x_{i}}\left[\left(\mu+\frac{\mu_{\text {turb }}}{\sigma_{\kappa}}\right) \frac{\partial \kappa}{\partial x_{i}}\right] .
$$

There is seen to be a multiplier on the rate of turbulent production, $P_{\kappa}$. That multiplier is symbolized by $\gamma$, the intermittency. The term $\gamma$ takes on values between 0 and 1 . It serves to reduce the rate of turbulence production in regions that are not entirely turbulent. Local values of $\gamma$ are found from two new transport equations which are

$$
\begin{gathered}
\frac{\partial\left(\rho u_{i} \gamma\right)}{\partial x_{i}}=P_{\gamma, 1}-E_{\gamma, 1}+P_{\gamma, 2}-E_{\gamma, 2}+\frac{\partial}{\partial x_{i}}\left[\left(\mu+\frac{\mu_{\text {turb }}}{\sigma_{\gamma}}\right) \frac{\partial \gamma}{\partial x_{i}}\right] \\
\frac{\partial\left(\rho u_{i} \Pi\right)}{\partial x_{i}}=P_{\Pi, t}+\frac{\partial}{\partial x_{i}}\left[\sigma_{\Pi, t}\left(\mu+\mu_{\text {turb }}\right) \frac{\partial \Pi}{\partial x_{i}}\right]
\end{gathered}
$$

The collection of (1)-(3) and (5)-(8) is often termed the transitional SST model. The symbols $P$ and $E$ represent rates of production and destruction of the transported variables. The symbol $\Pi$ is the turbulence adjunct function (sometimes called the transitional onset Reynolds number). The first equation, (7), provides values of the intermittency $\gamma$. As mentioned earlier, the intermittency takes on values between 0 and 1. Values of $\gamma$ near zero represent laminar regions while values that approach 1 occur in turbulent zones. Intermediate values of $\gamma$ are representative of flow that is partially laminar and partially turbulent. It should be noted 
that this definition of the intermittency differs from that sometimes found in the literature. Often, the intermittency is used as a multiplier of the eddy viscosity so that the eddy viscosity is reduced in regions where flow is partially turbulent. In the present work, the intermittency is utilized as a multiplier of the rate of turbulent energy production.

With respect to the turbulent adjunct function, $\Pi$, it is correlated to the local Reynolds number where intermittency first begins to grow (the critical value of the momentumthickness Reynolds number). So, solutions from (8) are utilized to calculate the value of the critical momentum thickness Reynolds number which, in turn, is used to modify (7) through the intermittency production terms $P$.

The output of the fluid dynamic model is the drag coefficient on the probe. This coefficient is a singular expression of the Reynolds number and will be employed in the following section.

Figure 1 has been prepared to illustrate some of the features of the computational mesh. The figure will convey the features common to the meshes employed on all of the $\mathrm{XBT}$ devices, although the mesh shown in the figure is meant to be illustrative. The image shows a probe with the mesh extending around the probe exterior as well as throughout the interior channel which houses the temperature sensor. Special boundary layer elements were employed at the surfaces of the probe. Two callouts are shown which illustrate the element deployment in those regions. It can be seen that the boundary-layer elements are thin prismatic elements aligned with the probe body. Those elements were carefully constructed so that the $y^{+}$was less than 1 .

For all investigated cases, a mesh-independence study was completed. This study involved the solution of the fluid flow problem with sequentially increasing element counts. The solutions were continued until the results were independent of mesh. For all probe shapes, the final mesh count was well over 1,000,000 elements. To provide some perspective on the mesh-refinement study, Table 1 has been prepared. That table lists the number of elements for two sequential simulations that were carried out on the T7 device. It can be seen that with a significant refinement of the mesh, the value of the drag coefficient has not changed appreciably. The results in Table 1, while shown for a single Reynolds number, are representative of findings carried out at all other Reynolds numbers.

The solutions to the fluid flow equations were found using the ANSYS CFX V13.0 software. In reality, the probes rotate during their descent. In the present simulations, rotation was ignored. It is expected that rotation may have a slight effect on the drag coefficient and may make it less sensitive to the Reynolds number. On the other hand, the present nonrotating results will be compared with experiments and the close agreement will be used to justify the present approach.

\section{Probe Dynamic Model}

With the drag coefficient of the probe available from the fluid dynamic simulations, it is possible to predict the probe fall rates through the ocean water. The first step in this stage is the

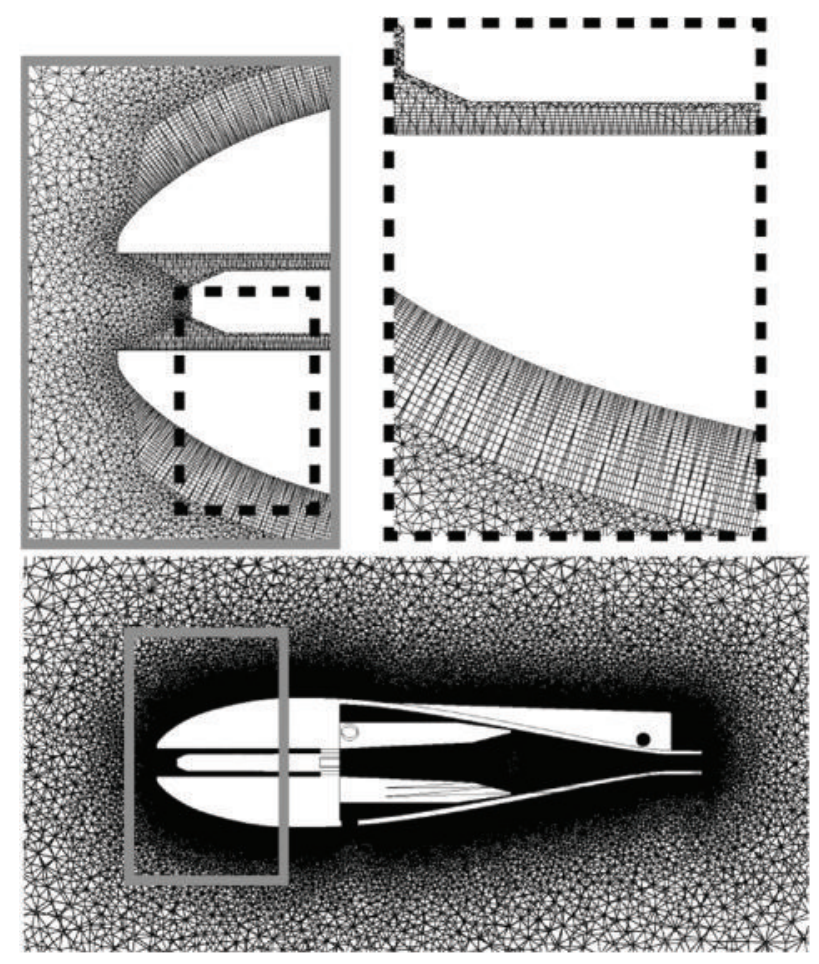

Figure 1: The computational mesh deployed in the fluid.

TABLE 1: Results of mesh-independence study, values of drag coefficient for the T7 device. Both calculations were completed for a $\mathrm{Re}=$ 950,000.

\begin{tabular}{lc}
\hline Number of elements & Drag coefficient \\
\hline $3,730,000$ & 0.103 \\
$14,280,000$ & 0.108 \\
\hline
\end{tabular}

development of a dynamic model that relates the drag force to the timewise variation in probe velocity. That relation begins with a balance of forces and momentum changes of the probe. Mathematically, this balance is expressed as

$$
F_{\text {net }}=F_{\text {buoy }}-F_{\text {drag }}=\frac{d\left(m_{p} V\right)}{d t}=m_{p} \frac{d V}{d t}+V \frac{d m_{p}}{d t} .
$$

Here, account is made for the change in mass of the probe as it descends through the water. It should be noted that the wire which is unspooled from the probe is not expected to exert any force on the probe. In addition, the unspooled wire has no velocity. When the drag and buoyancy forces are expressed in terms of the drag coefficient and the mass of the probe, the following expression is obtained:

$$
\begin{aligned}
\left(m_{p}-m_{w}\right) g-C_{d} \frac{1}{2} \rho V^{2} A & =m_{p} \frac{d V}{d x} \frac{d x}{d t}+V \frac{d m_{p}}{d x} \frac{d x}{d t} \\
& =m_{p} V \frac{d V}{d x}+V^{2} \frac{d m_{p}}{d x} .
\end{aligned}
$$


Equation (10) can be written in a forward-stepping algorithm that allows the determination of velocity at a new time, provided information at the current time is known:

$$
V^{\text {new }}=V+\frac{\Delta t}{m_{p}}\left[\left(m_{p}-m_{w}\right) g-C_{d} \frac{1}{2} \rho V^{2} A-V^{2} \frac{d m_{p}}{d x}\right] .
$$

It is (11) that will be employed to calculate the velocity at each timestep throughout the descent. It should be noted that this model is able to account for variations in the initial velocity of the probe (velocity of the probe when it enters the water) as well as variations in the linear mass of the wire, the diameter of the wire, and changes in the water temperature. This last issue deserves some detailed discussion. Historically, probe FREs are created by experimental correlation of XBT temperature values with more exact CTD results. Typically, XBT devices are dropped alongside CTD devices. Then, comparison of the temperatures between these devices allows construction of a FRE which takes the form

$$
\text { Depth }=A+B t+C t^{2} \text {. }
$$

For Class I probes (T4/T6/T7/DB), the recommended coefficients are $A=0, B=-0.00225$, and $C=6.691$ when depth is measured in meters and time is in seconds. For the Class II probes (T5), the constants are $A=0, B=-0.00182$, and $C=6.828$. However, the depth of a probe depends on local factors such as the specifics of the experiment (height of probe release above water), the details of the probe (size, mass, wire properties, etc.) and the local water temperature which affects the water viscosity. Consequently, when experiments are made under differing conditions, the FRE may no longer be valid. In particular, since most FREs are developed in tropical waters, their application to polar regions is questionable. The new method can account for variations in the water temperature and its impact on the viscosity. The variation is taken account of through the Reynolds-dependent drag coefficient. The definition of the Reynolds number used the probe length as the representative length.

\section{Results and Discussion}

The first set of results will focus on the values of the drag coefficients which characterize two classes of probes (Class $\mathrm{I}=\mathrm{T} 4 / \mathrm{T} 6 / \mathrm{T} 7 / \mathrm{DB}$ and Class II = T5). Additionally, the impact of laminar-to-turbulent transition will be explored. First, Figure 2 has been prepared which shows the drag coefficients on the Class I probes. It can be seen that the two solution methods provide somewhat different drag coefficients; the SST model predicts higher drag than the transitional model. A more detailed discussion of this difference will be provided later. Also shown in the figure are values of the drag coefficient which are estimated from Green [14]. A corresponding figure for the Class II probes is presented in Figure 3. There, it can be seen that the differences between the transitional and SST models is very small however (not discernibly different), the two methods exhibit a significant difference compared to

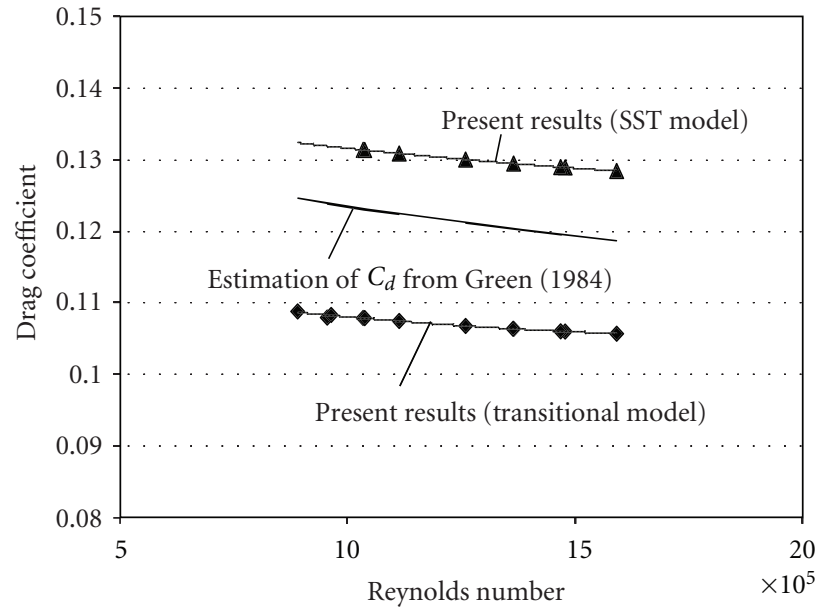

FIGURE 2: Drag coefficients for Class I probes, including SST model and transitional model results as well as drag coefficients from Green [14].

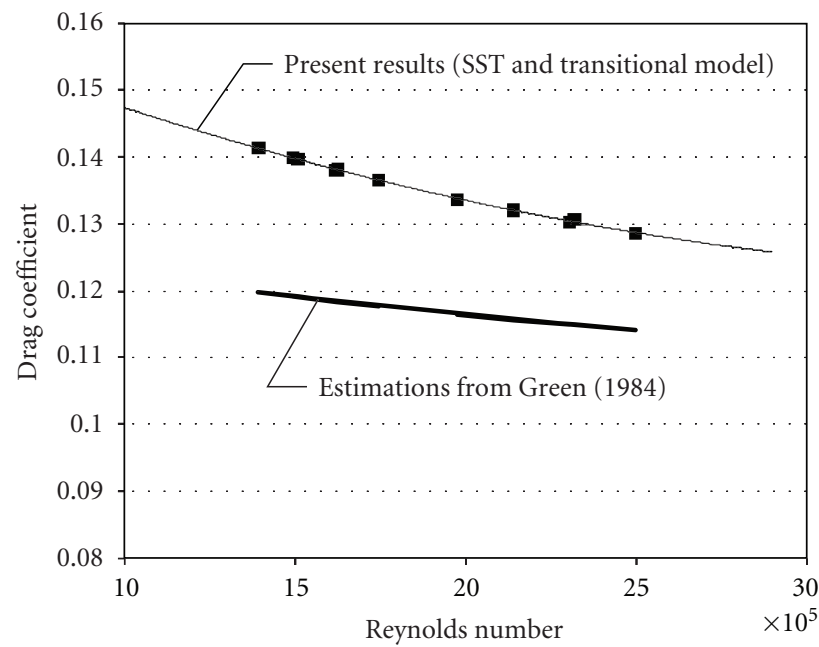

FIGURE 3: Drag coefficients for Class II probes, including SST model and transitional model results as well as drag coefficients from Green [14].

the values extracted from Green [14]. These results lead to the conclusion that for the T5 device, the effects of laminarto-turbulent transition is negligible and that solutions with a fully turbulent model are sufficient to use in the present situation.

With respect to the model differences in the Class I devices, depths were calculated with both the transitional and the SST drag coefficients. It was found that the quality of XBT-CTD match was improved when the SST-based coefficient was employed. It is believed that for the Class I devices, which are shorter in length than their Class II counterparts, flow separation on the downstream faces plays a larger role in drag. The transitional model has difficulty in predicting the location of separation in adverse pressure gradient situations. Consequently, it was decided to utilize the drag coefficient obtained with the SST model. 


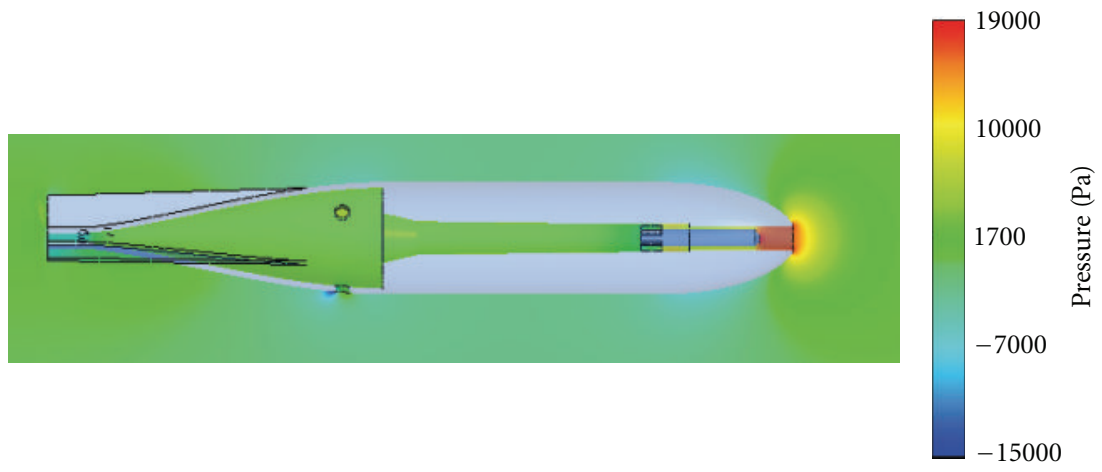

FIgURE 4: Pressure distribution in the fluid surrounding the probe (Class II probe).

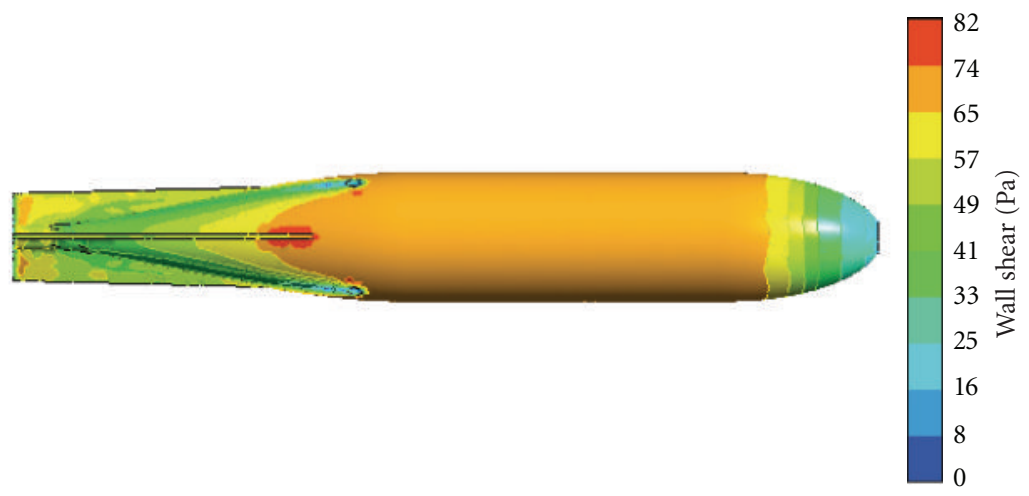

FIgURE 5: Distribution of surface shear stress (Class II probe).

For both classes of probes, the drag coefficients can be represented as functions of the Reynolds number. Those expressions are

$$
C_{d}=2.18 \times 10^{-15} \cdot \mathrm{Re}^{2}-1.10 \times 10^{-8} \cdot \mathrm{Re}+0.140,
$$

for Class I probes and

$$
C_{d}=2.74 \times 10^{-15} \cdot \mathrm{Re}^{2}-2.21 \times 10^{-8} \cdot \mathrm{Re}+0.1668,
$$

for Class II probes. The Reynolds number ranges are indicated by the figure axes.

Figure 4 has been prepared which shows the pressure distribution in the fluid near the XBT probe. In the figure, fluid is traveling from right to left. The figure shows that at the nose of the probe, there is a region of high pressure which decreases toward the upper and lower surfaces of the probe. Similarly, Figure 5 shows the variation of the shear stress on the surface of an XBT probe. It can be seen that the shear stress in the streamwise direction is low at the leading edge and trailing surfaces of the probe, as expected. The stress is more uniform along the length of the fuselage. The shear stress results presented in Figure 5 are representative of the results which can be extracted on any of the probe variants.

Next, displays of fluid flow patterns near the probe surface are shown in Figure 6. Here, representative images are exhibited which convey the basic features of the flow. It can

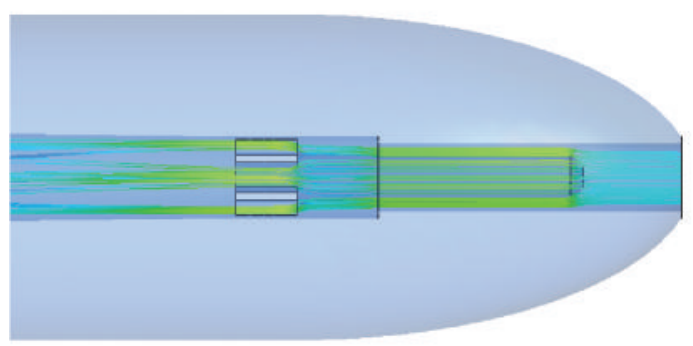

(a)

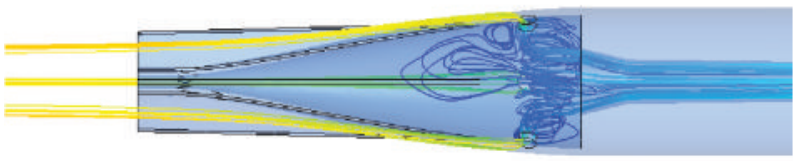

(b)

FIGURE 6: Streamline patterns through the center channel of a probe [31].

be seen that the flow is channeled in the streamwise direction as it enters the center channel of the probe. The fluid in this channel washes over the temperature probe before passing through the body and emptying into a downstream chamber. 


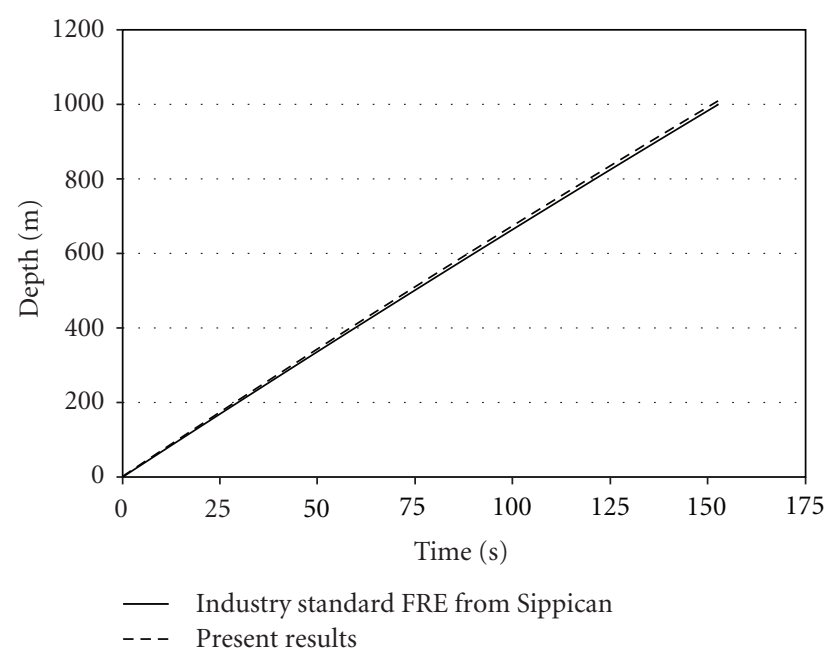

FIGURE 7: Comparison of depth calculated with the standard FRE and the new method.

In that chamber, there is flow recirculation and eddies which form before the fluid finally exits the probe interior.

In order to have confidence in the results presented here, it is necessary to make two comparisons. First, depth predictions will be compared with predictions obtained from the industry standard FRE. Second, comparisons between the new method and collocated CTD experiments will be made. An example of the first comparison is shown in Figure 7. The comparison from Figure 7 is taken from an experiment on Class II probes which was made in the Mediterranean Sea in May, 2011. It is seen that down to depths of $1000 \mathrm{~m}$, the new method is nearly identical with the standard FRE technique. Comparisons with Class I probes reveal a similar level of agreement.

Next, experiments with coincident CTD/XBT devices are made. Typically, temperature and depth results from CTD probes are considered exact and are used to calibrate XBT devices. Two sample experiments are shown. The results of the experiments are shown in Figures 8 and 9. Each figure has two parts (a) and (b). The (a) part of the figure focuses on the near-surface region of the descent. The (b) part shows the temperature data down to the deepest parts of the descent. The images are separated into the parts to allow a magnification of temperature differences in the near-surface region.

Each part has three curves. Those curves represent the "exact" temperature information from the CTD devices, the temperatures from the new method, and temperatures which are obtained using the standard FRE. The display of results in Figures 7, 8, and 9 show that the new method is capable of calculating the depth of XBT devices throughout their entire descent with accuracy that is approximately equal to the industry standard FREs. In Stark et al. [31], it was shown that a quantitative comparison of a large number (seventeen) comparisons of CTD/XBT temperatures revealed that the temperature results from the new method and the accepted FRE agree to within the accuracy of the temperature sensing device. These findings were further reinforced in Abraham

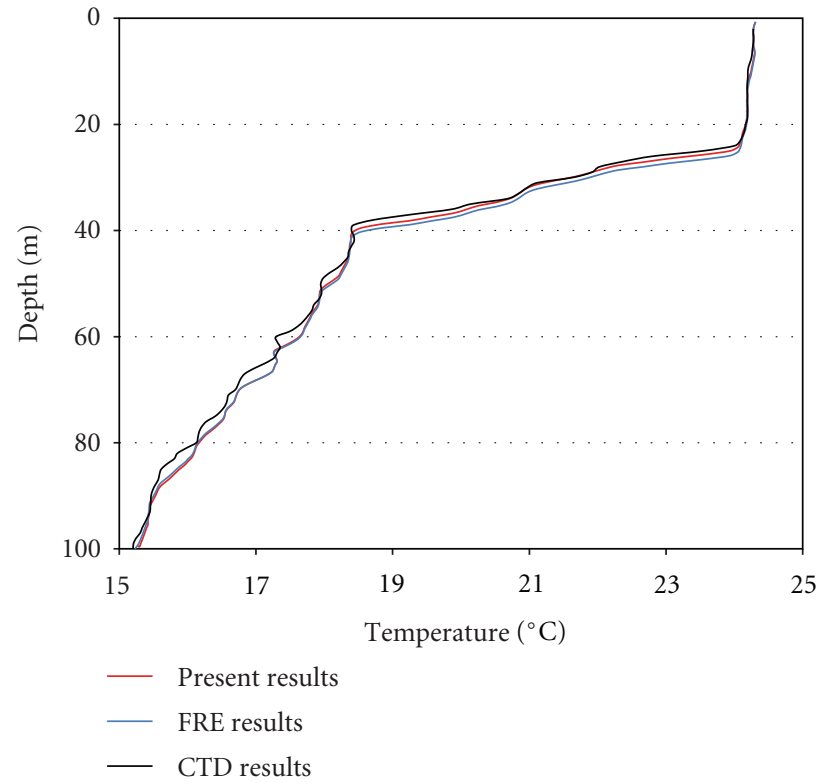

(a)

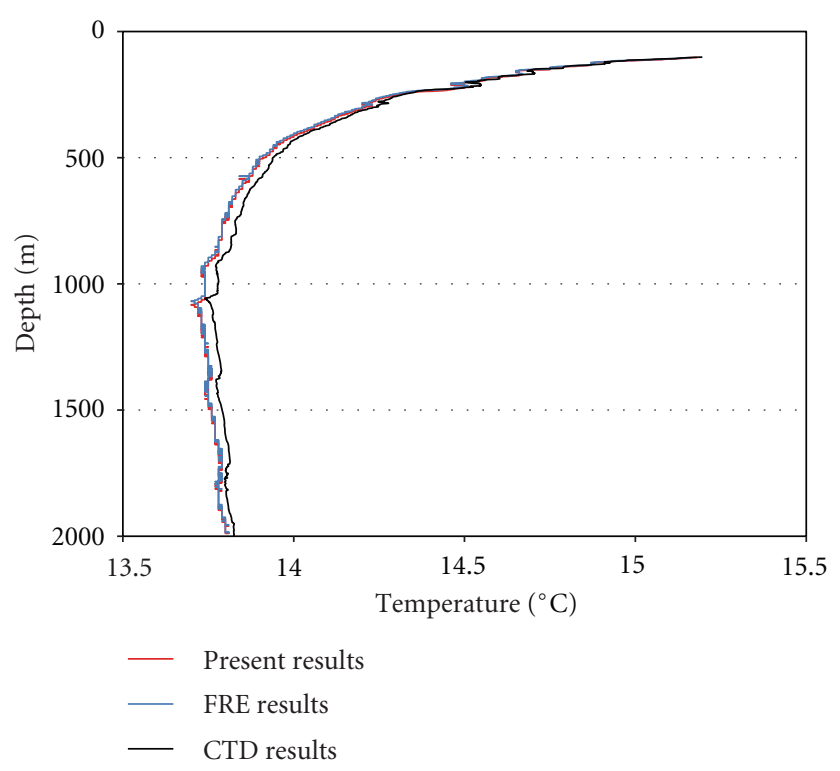

(b)

FIGURE 8: Comparison of the present method and the manufacturer FRE with a collocated CTD experiment.

et al. [29]. This finding provides further evidence that the new technique has some merit in predicting XBT depths and in evaluating the ocean temperatures and ocean heat content.

As stated earlier, one significant advantage of the new method is that it is able to accommodate changes in the probe design or the launching method. For instance, the new method can incorporate different launch heights, probe shapes and sizes, initial probe mass, linear mass of the wire, diameter of the wire, and so forth. 


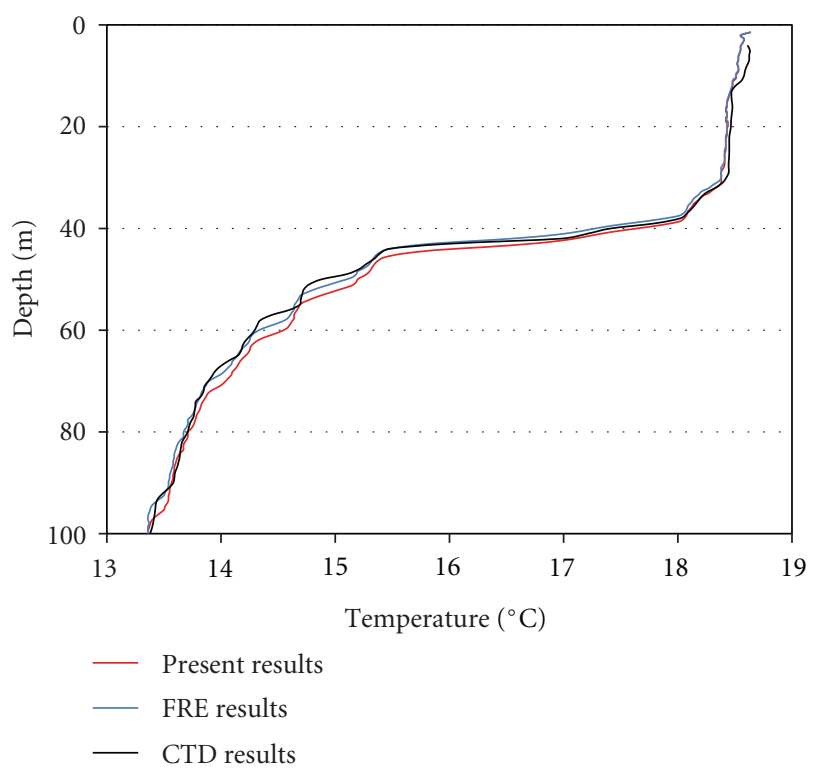

(a)

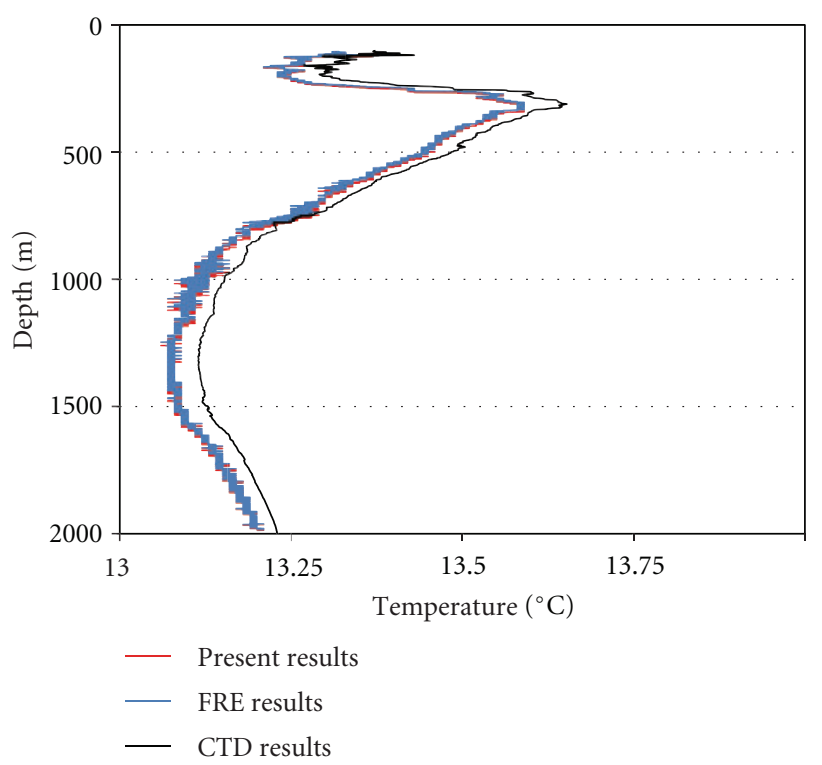

(b)

FIGURE 9: An additional comparison of the present method and the manufacturer FRE with a collocated CTD experiment.

\section{Concluding Remarks}

In this study, a new technique is presented to calculate depths of oceanographic temperature monitoring devices. Those devices, expendable bathythermographs, are launched into the ocean with high frequency each year. As the devices descend, they gather temperature information which, when combined with ocean depths, can provide ocean heat content assessments. XBT devices do not measure depth directly but rather determine depths from a correlative equation that is determined from experiment. This correlation, termed a Fall Rate Equation (FRE), is typically based on experiments carried out in tropical-water environments. FREs are incapable of handling variations in probe design, launch parameters, or water conditions. For instance, if the launch height or probe shape is changed, the FRE must be recalculated.

The new method, on the other hand, is based on a dynamic analysis of the probe which accounts for the forces exerted on the probe and the change in probe momentum. Necessary for the dynamic model is the drag coefficient on the probe. In this study, drag coefficients were determined on oceanographic devices for the first time (to the best knowledge of the authors). It was found that the drag coefficients were singular expressions with respect to the Reynolds number. With drag coefficients available, it was possible to calculate the depth of the XBT probes with accuracy that is comparable to the industry standard FRE.

It is hoped that this new method will be useful in reevaluating the archive of oceanographic temperature data and can be used to improve the accuracy of ocean heat content, and consequently, the role of oceans in storing excess energy from the surrounding environment.

\section{References}

[1] B. D. Santer, C. Mears, C. Doutriaux et al., "Separating signal and noise in atmospheric temperature changes: the importance of timescale," Journal of Geophysical Research D, vol. 116, no. 22, Article ID D22105, 2011.

[2] S. E. Wijffels, J. Willis, C. M. Domingues et al., "Changing expendable bathythermograph fall rates and their impact on estimates of thermosteric sea level rise," Journal of Climate, vol. 21, no. 21, pp. 5657-5672, 2008.

[3] V. Gouretski and F. Reseghetti, "On depth and temperature biases in bathythermograph data: development of a new correction scheme based on analysis of a global ocean database," Deep-Sea Research Part I: Oceanographic Research Papers, vol. 57, no. 6, pp. 812-833, 2010.

[4] S. Kizu, C. Sukigara, and K. Hanawa, "Comparison of the fall rate and structure of recent T-7 XBT manufactured by Sippican and TSK," Ocean Science Discussions, vol. 7, no. 5, pp. 1811-1847, 2010.

[5] P. N. DiNezio and G. J. Goni, "Identifying and estimating biases between XBT and Argo observations using satellite altimetry," Journal of Atmospheric and Oceanic Technology, vol. 27, no. 1, pp. 226-240, 2010.

[6] F. Reseghetti, "Performance of XBT systems in Mediterranean Sea (2003-2010)," in Proceedings of the XBT Bias and Fall Rate Workshop, Hamburg, Germany, August 2010.

[7] V. Gouretski and K. P. Koltermann, "How much is the ocean really warming?" Geophysical Research Letters, vol. 34, no. 1, Article ID L01610, 2007.

[8] S. Levitus, J. Antonov, and T. Boyer, "Warming of the world ocean, 1955-2003," Geophysical Research Letters, vol. 32, no. 2, Article ID L02604, 2005.

[9] S. Levitus, J. I. Antonov, T. P. Boyer, R. A. Locarnini, H. E. Garcia, and A. V. Mishonov, "Global ocean heat content 19552008 in light of recently revealed instrumentation problems," Geophysical Research Letters, vol. 36, no. 7, Article ID L07608, 2009.

[10] J. D. Boyd and R. S. Linzell, "The temperature and depth accuracy of Sippican T-5 XBTs," Journal of Atmospheric and Oceanic Technology, vol. 10, no. 1, pp. 128-136, 1993. 
[11] K. Hanawa, P. Rual, R. Bailey, A. Sy, and M. Szabados, "A new depth-time equation for Sippican or TSK T-7, T-6 and T4 expendable bathythermographs (XBT)," Deep-Sea Research, vol. 42, no. 8, pp. 1423-1451, 1995.

[12] P. Thadathil, A. K. Saran, V. V. Gopalakrishna, P. Vethamony, N. Araligidad, and R. Bailey, "XBT fall rate in waters of extreme temperature: a case study in the Antarctic Ocean," Journal of Atmospheric and Oceanic Technology, vol. 19, no. 3, pp. 391-396, 2002.

[13] S. Kizu, H. Yoritaka, and K. Hanawa, "A new fall-rate equation for T-5 expendable bathythermograph (XBT) by TSK," Journal of Oceanography, vol. 61, no. 1, pp. 115-121, 2005.

[14] A. W. Green, "Bulk dynamics of the expendable bathythermograph (XBT)," Deep Sea Research A, vol. 31, no. 4, pp. 415-426, 1984.

[15] F. R. Menter, "Two-equation eddy-viscosity turbulence models for engineering applications," AIAA Journal, vol. 32, no. 8, pp. 1598-1605, 1994.

[16] B. E. Launder and D. B. Spalding, "The numerical computation of turbulent flows," Computer Methods in Applied Mechanics and Engineering, vol. 3, no. 2, pp. 269-289, 1974.

[17] D. C. Wilcox, "Reassessment of the scale-determining equation for advanced turbulence models," AIAA Journal, vol. 26, no. 11, pp. 1299-1310, 1988.

[18] D. C. Wilcox, "Comparison of two-equation turbulence models for boundary layers with pressure gradient," AIAA journal, vol. 31, no. 8, pp. 1414-1421, 1993.

[19] F. Menter, T. Esch, and S. Kubacki, "Transition modelling based on local variables," in Proceedings of the 5th International Symposium on Engineering Turbulence Modeling and Measurements, Mallorca, Spain, 2002.

[20] F. Menter, R. Langtry, S. Likki, Y. Suzen, P. Huang, and S. Volker, "A correlation-based transition model using local variables, part I: model formulation," in Proceedings of ASME Turbo Expo Power for Land, Sea, and Air, Vienna, Austria, June 2004.

[21] J. P. Abraham, E. M. Sparrow, and J. C. K. Tong, "Breakdown of laminar pipe flow into transitional intermittency and subsequent attainment of fully developed intermittent or turbulent flow," Numerical Heat Transfer B, vol. 54, no. 2, pp. 103-115, 2008.

[22] E. M. Sparrow, J. C. K. Tong, and J. P. Abraham, "Fluid flow in a system with separate laminar and turbulent zones," Numerical Heat Transfer A, vol. 53, no. 4, pp. 341-353, 2008.

[23] R. D. Lovik, J. P. Abraham, W. J. Minkowycz, and E. M. Sparrow, "Laminarization and turbulentization in a pulsatile pipe flow," Numerical Heat Transfer A, vol. 56, no. 11, pp. 861879, 2009.

[24] J. P. Abraham and A. P. Thomas, "Induced co-flow and laminar-to-turbulent transition with synthetic jets," Computers and Fluids, vol. 38, no. 5, pp. 1011-1017, 2009.

[25] J. P. Abraham, E. M. Sparrow, and J. C. K. Tong, "Heat transfer in all pipe flow regimes: laminar, transitional/intermittent, and turbulent," International Journal of Heat and Mass Transfer, vol. 52, no. 3-4, pp. 557-563, 2009.

[26] J. P. Abraham, E. M. Sparrow, J. C. K. Tong, and D. W. Bettenhausen, "Internal flows which transist from turbulent through intermittent to laminar," International Journal of Thermal Sciences, vol. 49, no. 2, pp. 256-263, 2010.

[27] E. M. Sparrow, J. P. Abraham, and W. J. Minkowycz, "Flow separation in a diverging conical duct: effect of Reynolds number and divergence angle," International Journal of Heat and Mass Transfer, vol. 52, no. 13-14, pp. 3079-3083, 2009.

[28] A. P. Thomas and J. P. Abraham, "Sawtooth vortex generators for underwater propulsion," The Open Mechanical Engineering Journal, vol. 4, pp. 1-7, 2010.

[29] J. P. Abraham, E. M. Sparrow, J. C. K. Tong, and W. J. Minkowycz, All Fluid-Flow-Regimes Simulation Model for Internal Flows, Nova Science, Hauppauge, NY, USA, 2011.

[30] T. Gebreegziabher, E. M. Sparrow, J. P. Abraham, E. Ayorinde, and T. Singh, "High-frequency pulsatile pipe flows encompassing all flow regimes," Numerical Heat Transfer A, vol. 60, pp. 811-826, 2011.

[31] J. Stark, J. Gorman, M. Hennessey et al., "A computational method for determining XBT depths," Ocean Science, vol. 7, no. 6, pp. 733-743, 2011. 

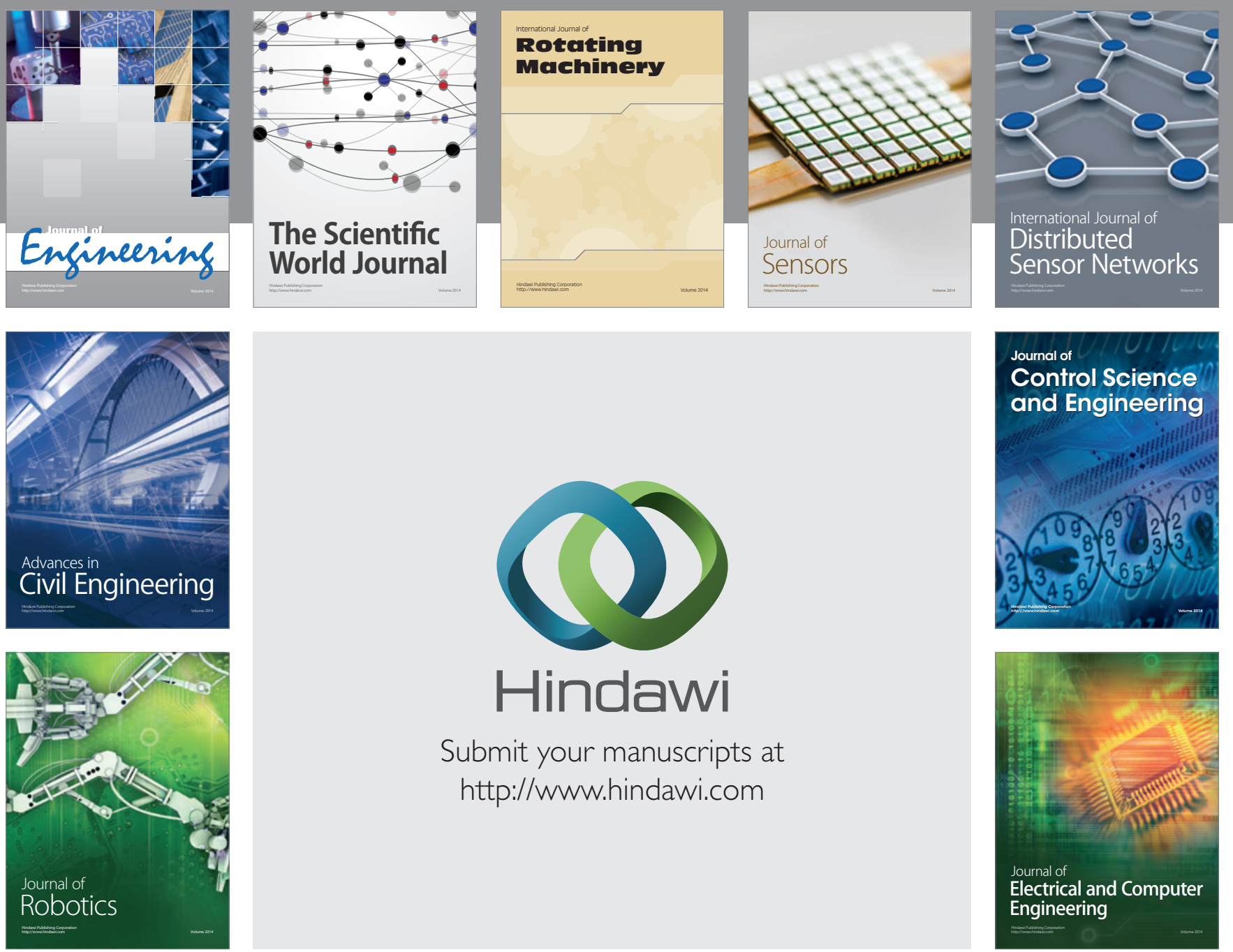

Submit your manuscripts at

http://www.hindawi.com
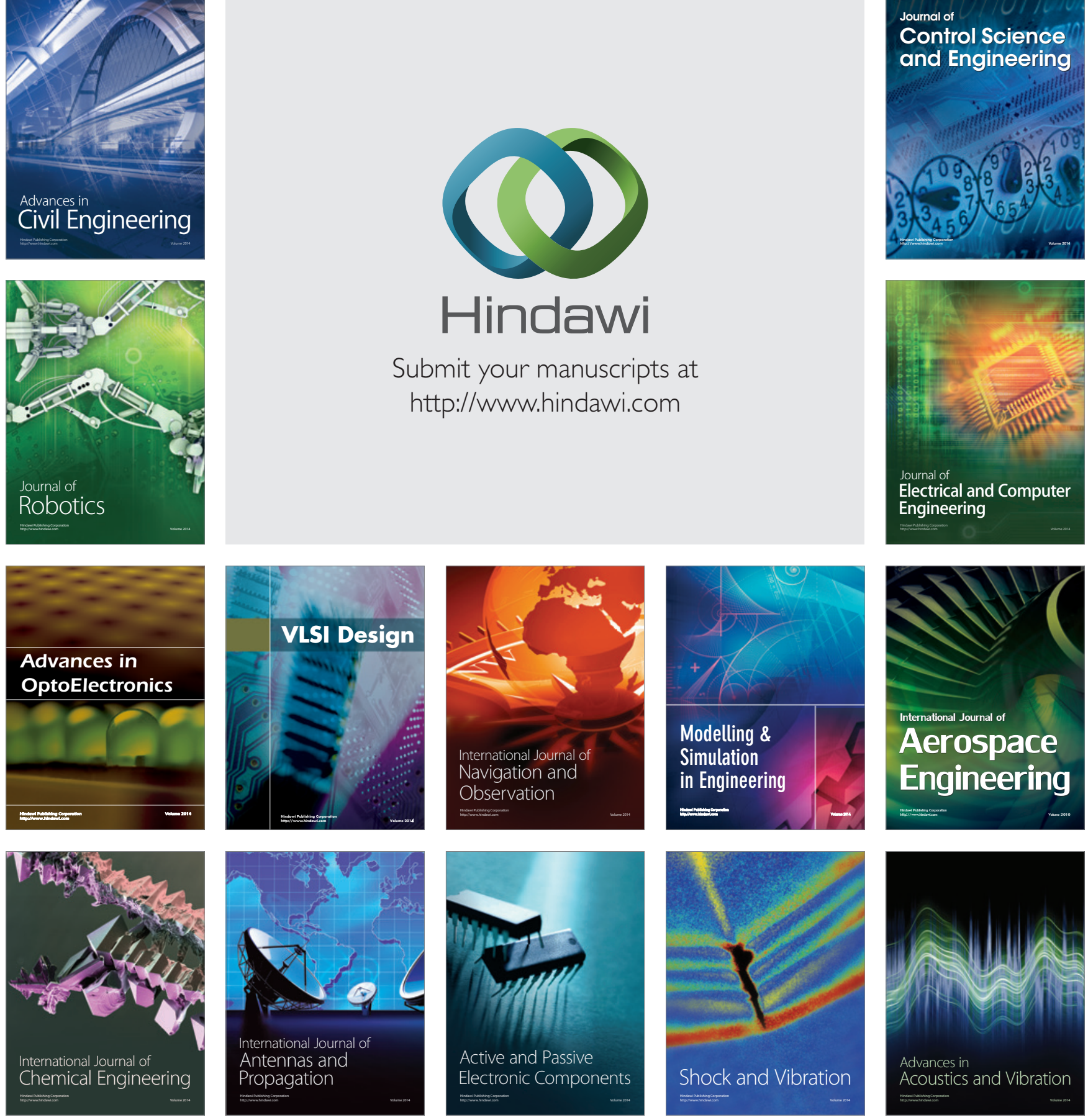